\title{
The Shaping of Inquiry: Histories of the Exact Sciences after the Practical Turn
}

\author{
Kristian Camilleri \\ School of Historical and Philosophical Studies, University of Melbourne, Melbourne, Australia \\ Email: kcam@unimelb.edu.au
}

Received 17 March 2015; accepted 11 April 2015; published 7 May 2015

Copyright (C) 2015 by author and Scientific Research Publishing Inc.

This work is licensed under the Creative Commons Attribution International License (CC BY). http://creativecommons.org/licenses/by/4.0/

c) (i) Open Access

\begin{abstract}
In this paper I examine three emergent trends in praxis-oriented historiography that have underpinned historical studies of the exact sciences covering the period from 1750 to 1960 . The first of these refers to what I call "tradition-centred" histories of scientific practice. This approach focuses on the formation of "cultures of practice" characterized by distinctive epistemic styles, which distinguish them from other such cultures. The second involves "tool-centred" histories of practice. This approach focuses on the way in which tools and techniques of inquiry open up new fields of inquiry, and the way in which the crafting of new tools and the refashioning of existing ones shape the dynamics of scientific practice. The third approach I examine relates to "actor-centred" histories, which typically take the form of biographical accounts focusing on the motivations, judgments and choices of individuals that shape scientific inquiry. This provide a useful analytic framework, in piecing together a broad picture of the different ways in which scientific inquiry is shaped and structured, and to see more clearly how different historiographical approaches complement one another in enriching our understanding of scientific practice.
\end{abstract}

\section{Keywords}

Scientific Practice, Historiography, Cultural History of Science

\section{Introduction}

“The conduct of scientific inquiry”, wrote John Dewey in 1938, "whether physical or mathematical, is a mode of practice; the working scientist is a practitioner above all else, and is constantly engaged in making practical judgements: decisions as to what to do and what means to employ in doing it” (Dewey, 1986: p. 163). Dewey’s conception of science did not gain much traction among contemporary historians of science, who at that time tended to be either Marxist in their orientation, or lean more towards the intellectualist history of science of 
Alexandre Koyré. It was not until the 1980s that historians of science, influenced by post-Kuhnain sociology of scientific knowledge and social constructivism, began to take "scientific practice" seriously as an object of study. In place of the Marxist and intellectual histories of the 1950s and 60s, a new perspective emerged, which centred around "a description of science as an activity, rather than of knowledge as a product derived from that activity" (Rouse, 2003: p. 107). Capturing the essence of this new perspective, Hasok Chang writes, "a serious study of scientific practice must be concerned with what it is that we actually do in scientific work. This requires a change of focus from propositions to activities" (Chang, 2011: p. 249).

By the 1990s, scholars were proudly proclaiming the "practical turn" as having moved beyond the highly idealized conceptions of science, which emphasized grand theories and conceptual worldviews (Golinski, 1990; Pickering, 1992; Buchwald, 1995). An important aspect of this shift was the emergence of a wave of new studies in the 1980s and 90s focusing on experiment. These studies challenged the standard accounts of science developed by Popper, Kuhn and Lakatos, which typically focused on theory change and which had tended to view experiment as "the handmaiden of theory". Historians and philosophers of science increasingly came to see experiment as having "a life of its own", and in many cases, not guided by, or even dependent on, relevant theory of the phenomena under investigation. Historical studies showed that experimental investigations of new phenomena or novel effects were often not motivated by the aim of testing or constructing new theories, but emerged from of programs of exploratory research drawing on several converging lines of inquiry (Steinle, 2002; Buchwald \& Hong, 2003).

But in addition to this, theory came to be reconceptualised. The practical turn, it is true, has often been portrayed as entailing a shift from "theory" to "practice". This judgment, as Galison and Warwick have noted, was in part due to the mistaken assumption that "while experiments can be historicised through the material culture and hands-on work of the laboratory, theories are isolated, ready-made products, which transcend the historical time and place of their making” (Galison \& Warwick, 1998: p. 288). Yet, historians became increasingly interested in forms of "theoretical practice", exemplified in the use of mathematical techniques, theories, analogies and models. Here attention shifted from "theories as finished products" to "theories in the making".

The difficulties associated with a history of scientific practice were apparent from the outset. Reconstructing past practices, which are often invisible to the traditional methods of textual analysis, presented formidable challenges to the historian. Perhaps equally challenging was the task of constructing a new conceptual framework and a precise vocabulary for thinking and talking about scientific practices. This was a subject that generated much debate in the 1990s (Buchwald, 1995). A further difficulty was the sheer overwhelming scope of practices-which now seemed to encompass everything from disciplinary history, to funding and material resources, to social and cultural norms, as well as the actual conduct of scientific research. Yet, over the last 25 years, much excellent work has been produced dedicated to scientific practice. Here I want to take this opportunity to take stock and ask what new insights about the dynamics of science have emerged from the practical turn. What has it yielded? To what extent has it enriched our understanding of the dynamics of scientific change? What kind of historiographical approaches have proved fruitful and illuminating?

In attempting to address these questions, I must be selective. A great deal of interest in scientific practice over the past three decades has been primarily concerned with the process by which scientific knowledge is generated. Sociologists of scientific knowledge, social constructivists and philosophers of science in the 1980s and 90s turned their attention to a range of questions relating to the resolution of scientific controversies, the making of scientific discoveries, and the construction or establishment of scientific facts. Such questions concerning the production of knowledge have also been an important stimulus for the revitalization of the integrated approaches to the history and philosophy of science as well as the renewed interest in historical epistemology (Feest \& Sturm, 2011).

Yet scientific practices have their own histories, and thus they may also be studied in their own right. In this paper I turn my attention to historical studies that have attempted to uncover the historical conditions under which, and the means by which, forms of practice and fields of inquiry emerge, are sustained, and undergo change. Not only does scientific practice take place under conditions shaped by social and cultural forces; it also generates and necessitates its own specific patterns of cultural, social and epistemic development. This is not to deny that scientific practices are undertaken with the aim of acquiring knowledge, nor does it necessarily entail skepticism or relativism. But the primary object of historical interest here is the practices themselves and what conditions give shape, structure and direction to scientific inquiry, rather than the epistemological question of how such practices produce knowledge. 
In this paper I examine three emergent trends in praxis-oriented historiography that have underpinned historical studies of the exact sciences covering the period from 1750 to 1960. While the examples I draw on in this study are taken from the history of natural philosophy, physics and chemistry, the general historiographical approaches in many cases apply more generally to the history of other sciences. The first of these trends refers to what I call "tradition-centred" histories of scientific practice. This approach focuses on the formation of "cultures of practice" characterized by distinctive epistemic styles, which distinguish them from other such cultures. Much recent scholarship in this direction has placed emphasis on the systems of pedagogy that sustain such cultures. The second involves "tool-centred" histories. This approach focuses on the way in which tools and techniques of inquiry open up new fields of inquiry, and the way in which the crafting of new tools and the refashioning of existing ones shape the dynamics of scientific practice. The third approach I examine relates to "actorcentred" histories, which typically take the form of biographical accounts focusing on the motivations, judgments and choices of individuals that shape scientific inquiry. These three approaches are, to a certain extent, "ideal types" in the Weberian sense, and indeed many historical accounts encompass more than one of these historiographical approaches. However, they provide a useful analytic framework through which to reflect on how "practice" has been studied in histories of the exact sciences.

The accretion of piecemeal historical studies that have emerged over the past three decades has led a number of historians of science to lament that much recent work has lost sight of "big picture". I think that cause for despair is premature. My sense is that we as yet lack a sufficiently detailed understanding of how the local microhistories, which currently proliferate, fit together. To this end, my aim in this paper is not to lay down an overarching historiographical framework, which might serve as a guide for the production of ever-more fine-grained historical studies, but to draw on existing historical studies in the exact sciences, in piecing together a broad picture of the dynamics of scientific practice. The task before us is to synthesize what we have already learned about the exact sciences, and to see more clearly how different historiographical approaches complement one another in enriching our understanding of scientific practice. While this paper can only be preliminary step in this direction, my hope is that this kind of synthetic approach might contribute to the articulation of a new "image of science" that has crystallized out the various strands of the practical turn.

\section{Tradition-Centred Histories of Scientific Practice}

\subsection{Different Ways of Doing Science: Cultures of Scientific Practice}

Kuhn's Structure of Scientific Revolutions continues to be a source of inspiration for historians and philosophers of science. Yet the Kuhnian image of science, grounded in notions of paradigm, crisis and revolution, has been subjected to extensive criticism. While Kuhn's work has undoubtedly offered historians, philosophers and sociologists with many intriguing insights, and did much to break the hold of the positivist view of science in the Anglophone world, historians struggled to find historical episodes that conform to Kuhn's patterns of paradigm change. Increasingly, historians have become accustomed to see physics, and other sciences for that matter, as "composed of subcultures with different dynamics" (Galison, 1999: p. 143). Peter Galison's work has done much to inform this new conception of science. One of the enduring insights to have emerged from his landmark study of $20^{\text {th }}$ century physics, Image and Logic, was that over the course of the $20^{\text {th }}$ century, practices of experiment, theory and instrumentation fragmented into "quasi-autonomous subcultures", each of which with "its own rhythms of change" and "its own standards of demonstration" (Galison, 1999: p. 143). Contrary to the Kuhnian view, Galison argued that "breaks in theoretical practice may occur during a time of continuity in instrumental practice", and vice versa (Galison, 1997: p. 14). Indeed, "the practice of experimental physics in the quantum-mechanical revolution of 1926-27 was not violently dislocated despite the startling realignment of theory; spectroscopy continued unabated as did measurement of specific heat and black-body radiation” (Galison, 1999: p. 143). And within these subcultures, one can find distinct traditions, each of which is characterised by different forms of inquiry and patterns of argument. This serves as an important corrective to the Kuhnian image of physics "as constituting a single, monolithic structure", which undergoes periods of normal science, disrupted by crisis and revolution.

But how should we characterise such subcultures or traditions? Jed Buchwlad has argued that in grasping different traditions of practice, the historian must do more than identify a miscellaneous collection of disparate techniques typically employed by the scientist, but must look for "a powerful, motivating, and structuring force that unites them, or certain aspects of their work, in a common endeavour" (Buchwald, 2000: p. 208). How one 
construes this 'structuring force' very much depends on whether the object of historical analysis is a local culture, or a tradition extending over a long period. Hasok Chang makes a similar point in suggesting the various epistemic activities that form part of a tradition do not occur in isolation-rather they are brought together in a "system of practice" in which "a coherent and interacting set of activities performed with a view to achieve certain aims". The coherence of a system of practice, as Chang makes clear, "consists in the various activities coming together in an effective way toward the achievement of the aims of the system” (Chang, 2011: p. 252).

Historians have brought to light the distinctiveness of certain cultures and traditions, by means of synchronic comparisons with other rival traditions, or diachronic comparisons. This has often taken the form of identifying certain "styles" of research, though historians and sociologists have used the term in a variety of ways since the rediscovery of Ludwik’s Fleck's work in the 1980s (Zittel, 2012). Nonetheless, the notion of styles has proved to be a useful historiographical concept for elucidating the distinctive nature of subcultures or research traditions (Vicedo, 1995). In contrasting the "concrete” style of the Manchester school of British chemistry with the "abstract” style of French chemistry in the 1920s, Mary Jo Nye has argued that British chemists tended to rely heavily on "visual imagery" in attempting to form theories about the mechanisms underlying organic reactions, whereas "the goal of scientific explanation among French scientists was a finely crafted theory of generalized abstractions, expressed in rigorous mathematics” (Nye, 1993: p. 34). In defining the concept of an epistemic style, Jane Maeinschein writes:

An epistemic style involves commitments as to what seeks as the outcome of science, as to what counts as the appropriate procedures for gathering knowledge, and as to how to know when one has achieved knowledge at all... These sets of commitments... cluster into different ways of doing science... they deal with ways of coming to know, what counts as knowing, and what counts as the objects of knowledge. Moreover they characterize patterns of practice (or the doing of scientific work), rather than the content of theories (Maienschein, 1991: p. 410).

Many examples of 'styles', in the sense here outlined by Maienschein, can be found in the history of the exact sciences. Indeed much historical work has been devoted to characterising and explaining the emergence of styles. The rise of mathematical physics of the decades of the $19^{\text {th }}$ in France-exemplified in the new approach to the study of light, heat, electricity and magnetism — was associated with an emphasis on the use of precision instruments, the importance of obtaining numerical results from experiment, and the replacement of geometric by algebraic forms of mathematical representation (Frankel, 1977; Buchwald \& Hong, 2003: p. 168). These characteristics were notably absent from the experimental tradition of the $18^{\text {th }}$ century. Keneth Caneva has also argued that "a new approach to the study of physics had already begun to emerge in the late 1820s" in Germany, which signaled a shift from "concretizing science” to "abstracting science”. Whereas the former was characterized by an emphasis on qualitative experimentation, a commitment to the primacy of experience as the source of scientific knowledge, and a preference for physical explanation over mathematical description, the latter was "marked by an overriding concern with quantitative measurement”, the use of abstract mathematical constructions and the hypothetico-deductive method (Caneva, 1978: p. 66).

The clash of the "image" and "logic" traditions in experimental particle physics during the $20^{\text {th }}$ century provides another example. As Galison has shown, both traditions were based on the use of instruments designed to disclose the existence of sub-atomic particles or effects, but they each incorporated quite different types of particle detectors, and operated with different standards of evidence for what counted as the detection of a particle. The image tradition, which came into its own with the development of the Wilson's could chamber in the 1910s, aimed at producing images of particle tracks "of such clarity that a single picture could serve as evidence for a new entity or effect”. The logic tradition, which emerged in the late 1920s and 1930s with the development of cosmic ray physics, on the other hand, "used electronic counters coupled in electronic logic circuits" designed to "aggregate masses of data to make statistical arguments for the existence of a particle or effect” (Galison, 1997: p. 19). Both traditions evolved over the course of the $20^{\text {th }}$ century, and increasingly sophisticated instruments were devised on both sides, but they remained in fundamental tension with one another until the 1970s, when a new generation of instruments emerged, which brought together aspects of both traditions in a new technological synthesis.

Galison's work shows that the image and logic traditions were grounded in different epistemic styles, but they were also grounded in different forms of cultural practice. Each depended on its own system of values, technical skills, epistemic norms, patterns of argument and discursive practices, which formed the basis for particular 
research tradition. "Understanding science as a cultural activity”, as Galison and Warwick have argued, "means learning to identify and to interpret the complicated and particular collection of shared actions, values, signs, beliefs and practices by which groups of scientists make sense of their daily lives and work” (Galison \& Warwick, 1998: p. 288).

\subsection{The Shaping of the Scientific Self and the Role of Pedagogy}

The formation of scientific traditions, and cultures of practice cannot be understood without understanding the ways in which scientific practitioners come to embody the values, skills, norms, and styles of the culture to which they belong. As David Kaiser puts it: "Scientists are made, not born” (Kaiser, 2005b: p. 1). To this extent, the historical study of cultures of scientific practice has become closely linked to what Daston and Galison have called 'the history of the scientific self'. The natural philosopher or the scientist must be inculcated with certain capacities to become a scientific practitioner. These capacities are "realized and reinforced by specialized techniques of the self” (Daston \& Galison, 2007: p. 38). The capacity to carry out particular forms of objective inquiry requires, somewhat paradoxically, a certain kind of subjectivity.

Much of the recent scholarly interest in scientific practice has focused on scientific pedagogy in producing scientific inquirers. A new wave of studies over the past fifteen years have emphasized the crucial role of pedagogy not only in making scientists, but in defining traditions, disciplines, and fields of inquiry. "Science pedagogy", as Katherine Olesko writes, is "central to understanding the contours of scientific practice, the formation of scientific personae, and indeed the ability of science as an enterprise to reproduce and survive” (Olesko, 2006: p. 863). In educational settings, cultures of inquiry are forged, in which individuals acquire the norms, values, techniques, habits, and skills that make possible the epistemic activities in accordance with certain scientific styles

This renewed emphasis on pedagogy has followed from the realization, already apparent in much earlier work going back to Fleck, Polanyi and Kuhn, that scientific work involves a form of unarticulated (though not necessarily inexpressible) skill, or know-how, which must be acquired through forms of training. Historians of science, drawing on the resources of cultural anthropology and methods of replicating past experiments, have done much to illustrate the way in which experimental practice requires forms of skill or gestural knowledge that can only be acquired "through active participation or enculturation” (Sibum, 1995). More recently, Daston and Galison have studied the history of images in scientific atlases, in revealing the way in that particle physicists and astronomers had to learn new "ways of seeing" in the first half of the $20^{\text {th }}$ century. The capacity to identify the existence of a new sub-atomic particle in the cloud chamber, or to classify a star, using methods of spectrographic analysis and parallax measurements, required forms of 'trained judgment', which could only be acquired over an extended period of time through a familiarity with the images of particle tracks and spectral data (Daston \& Galison, 2007).

Theoretical work is also a matter of skilful practice. One of Kuhn's enduring insights, as Warwick and Kaiser point out, has been to show that "the physicist's knowledge does not reside in mental retention of definitions and rules, but in the embodied ability to "perform" the solution to a problem when required to do so" (Warwick \& Kaiser, 2005: p. 395). What defines a paradigm, on this view, is not so much a set of beliefs or ontological commitments, but rather knowing how to apply certain theoretical tools in concrete situations. This lies at the heart of Kuhn's re-characterization of a paradigm as a "disciplinary matrix”, rather than a "conceptual worldview”. Kuhn's insights on how scientists acquire such abilities in their training has stimulated much further work, but Kuhn never developed them himself in any systematic fashion. A more comprehensive approach to this question was pursued by Foucault in Discipline and Punish (Foucault, 1977). There Foucault argued that from the late $18^{\text {th }}$ century onward, new forms of "disciplining” gradually emerged, in which individuals were subjected to "petty forms of coercion” designed to inculcate certain forms of normalised behaviour, but also importantly "to generate new capabilities in human beings” (Warwick \& Kaiser, 2005: p. 406). As Olesko points out, for Foucault, "disciplining literally made the modern individual, and hence was constitutive of the formation of modern society” (Olesko, 2006: p. 867). It should therefore come as no surprise that the appearance of new forms of practice in the exact sciences coincided with the "pedagogical revolution" that Foucault identified as having emerged in the late eighteenth century.

Historical studies during the 1970s began to explore the emergence of new educational institutions, though often without explicit Foucaultian overtones. Eugene Frankel, in his study of the rise of mathematized experi- 
mental physics in Napoleonic France, has argued that the sweeping educational reforms, in particular the establishment of the Ecole Polytechnique in 1794 and the Société d'Arcueil in 1807, created the conditions for the emergence of a new kind of French physics, exemplified in the work of Biot, Fresnel, Malus and Ampère, all of whom were graduates of the Ecole Polytechnique (Frankel, 1977; Fox, 1974). Keneth Caneva has also argued, in a similar fashion, that the "profound reformation of the German university system" was instrumental in the emergence of a shift from "galvanism" to "electrodynamics" in the 1830s and 40s (Caneva, 1978). More recently, Andrew Warwick's pioneering work on the Cambridge Mathematical Tripos system, has shown how the pedagogical practices and vocational training structured around the Tripos examination were instrumental in the formation a distinctive tradition of mathematical physics in Britain (Warwick, 2003). Further studies have revealed the Maxwellian tradition that emerged from Cambridge was characterized by a style of physics that favoured the use of variational principles, boundary conditions and continuum analysis (Buchwald \& Hong, 2003).

Much recent work has also been devoted to the way in which formation of 'research schools' in the $19^{\text {th }}$ and $20^{\text {th }}$ centuries served to blur the distinction between pedagogy and active research. As Nye has argued, the 'research school' provides the historian with unit of analysis from which to "understand more fully the origin and perpetuation of the idea of scientific style ... as a way of doing science”. One can find certain styles of research present in the work of individuals, "but their perpetuation, if not their origin, lies in scientific traditions passed on through formally institutionalized schools-for example, universities-and through informally constituted "schools", which include "research schools" (Nye, 1993: p. 32). Nye has argued that the "abstract-concrete dichotomy", which characterized the contrasting styles of chemistry that emerged in France and England in the 1920s, was based "in the pedagogical traditions in the two countries". Unlike their French counterparts, members of the "Manchester school" of organic chemistry had not typically undergone a rigorous grounding in mathematics. In France, where mathematics enjoyed greater cultural prestige than it did in England, the leading physical chemists were graduates of Ecole Polytechnique and the Ecole Normale Supériere (Nye, 1993).

Research schools may also be founded by individuals, whose style becomes the model for future research carried out by students. Kathryn Olesko has traced the influence of Franz Neumann's mathematical-physical seminars, founded in the 1830s in Königsberg. The seminars were deigned to give students a grounding in mathematical methods and as well as techniques of precision measurement that required the systematic controlling of experimental errors. The legacy of Neumann's "ethos of exactitude" lived on in the work of physicists such Voigt and Kirchhoff (Olesko, 1991). More recently, Suman Seth has illustrated the way Arnold Sommerfeld made Munich one of the leading centres for training theoretical physicists in the early decades of the $20^{\text {th }}$ century. During this time, Sommerfeld forged a distinctive style of physics, which Seth labels the "physics of problems" (Seth, 2010). Many students of the "Munich school", most notably Heisenberg, Pauli, Bethe and Debye (all of whom won Nobel prizes) went on to make fundamental contributions to the development of quantum theory in the 1910s and 20s, sometimes while they were still in the process of completing their apprenticeships as doctoral students. Through advanced seminars and specialized courses, Sommerfeld fostered in his students an ability to improvise creatively through the use of innovative techniques.

This last point is of crucial importance. As Warwick and Kaiser have stressed, while "research practices are always pedagogically conditioned, they are not determined” (Warwick \& Kaiser, 2005: p. 401). In this sense, improvisation is always possible, but such improvisation is only made possible by drawing on existing sets of skills and techniques. The significance of this point for a deeper understanding of scientific practice should not be underestimated. While philosophers have often sought to understand scientific problem-solving as the application of rules or the following of a prescribed method, the particular approach a scientist brings to a problem will be based largely on the skills they have acquired in their prior training, but which they may adapt to new situations.

\subsection{Scientific Traditions in Wider Social Context}

Whereas Foucault, and to a lesser extent Kuhn, were content to focus their attention on the social practices and the specific training regimes by means of which individuals were subjected to disciplining, historians of science since have gone further in studying the wider historical context in which particular disciplinary regimes arise. As Katherine Olesko points out, "what has been studied inside educational settings has much to do with what is outside them" (Olesko, 2006: p. 864). This is strikingly evident in the formation of the Ecole Polytéchnique in 
France, which was originally an institution for the training of military engineers during the turmoil of the French Revolution. Keneth Caneva has argued that the shift from the "concretezing" to the "abstracting" modes of scientific practice in German physics in the 1820s and 30s can only be understood against the background of the profound sense of "disillusionment with the dominant modes of university instruction" that arose in the first quarter of the $19^{\text {th }}$ century (Caneva, 1978: p. 126). The reform of the German university reflected a "generational split" that coincided with the social and political upheaval of the Napoleonic wars, and the emergence of the new ideology of Bildung and Wissenschaft (Caneva, 1978: p. 125). In these examples, we can see how the transformation of modes of scientific practice, undergirded by systems of education, reflects "the social, cultural, political, and economic systems of which science is a part and without whose support it would not exist" (Olesko, 2006: p. 871).

Much recent work has also brought to light the importance of systems of patronage for both pedagogical training of scientists. "The ascendence of geophysics" in the $20^{\text {th }}$ century, as Oreskes and Doel point out, "reflected, and was fundamentally shaped by, the demands of the second industrial revolution, and particularly by the needs of military patrons during World War II and the Cold War”. The increased funding, which followed the recognition of the strategic value of geophysics and oceanography for military applications, led to "the development of research institutions and university graduate programs", as well as "new instrumental practices, and increased professional opportunities for individuals trained in these techniques" (Oreskes \& Doel, 2008: p. 552). Over the course of the $20^{\text {th }}$ century, the geophysical tradition, grounded in a laboratory culture that "promoted the values of exactitude, precision, and control", slowly eclipsed the geological tradition, which "promoted the values of authenticity, accuracy, and completeness" associated with fieldwork (Oreskes \& Doel, 2008: p. 549). Social, economic, and political history can become relevant to the study of shifting patterns of scientific practice, via the mediation of institutional and educational reform.

Historical studies over the past two decades have shed light on the social, political or economic contexts in which different scientific traditions, modes of practice, or forms of inquiry, may appear. Such contexts should be seen, not as causes, but rather as conditions of possibility. The French Revolution, or the Second World War did not cause new kinds of physics to emerge, but they did provide the social and political conditions under which new kinds of inquiry became possible. Here I follow James Elwick, in defining a context as "a space of possibilities", in which different styles or patterns of practice may emerge (Elwick, 2012). If we adopt such a view, historical explanations that make appeal to wider social, cultural and political contexts need not be seen as alternatives to "internalist explanations", nor as depriving the historical actors of their agency. Contextualist approaches can provide valuable insights into the conditions under which scientific traditions come into being, without providing causes for their emergence. However, such approaches cannot stand on their own - they must be supplemented by accounts of the actual dynamics of scientific practice, which reveal the ways in which scientific traditions evolve and undergo transformation over time.

\section{Tool-Centred Histories of Scientific Practice}

\subsection{The Dynamics of Scientific Change}

Whereas much post-Kuhn philosophy of science has tended to see scientific revolutions in terms of theory change, much recent work in the history of exact sciences has emphasized the importance of the invention of new research tools for an understanding of historical patterns and processes of change. In many cases, the development of new scientific instruments and experimental and theoretical techniques enable scientists to get to grips with problems that were previously beyond their grasp, opening up new fields of inquiry and new objects of investigation. "By bringing instruments front and centre", Galison contends, we obtain a different picture of the history of physics, which can "only awkwardly classed under the old rubrics 'internal intellectual history' and 'external sociological history'". Such a history, of course, "must be a technical history", but it "is necessarily also part labor history, part sociology, and part epistemology" (Galison, 1997: p. 5). One might add that it is also part cultural history. The quest for increasingly accurate measuring instruments, such as the thermometer and the torsion balance in the 1780s, reflected the "culture of precision" and the "quantifying spirit" of the late $18^{\text {th }}$ century (Heilbron, 1990; Wise, 1997).

Yet the "tools of inquiry" need not be confined to the material culture of the laboratory. Much recent work in the history of the exact sciences has brought to light the way in which the introduction of new concepts, "mathematical tools" and methods of calculation have opened up new fields of research and forms of inquiry. Ursula 
Klein has also shown how the introduction of chemical formulas (such as $\mathrm{H}_{2} \mathrm{O}$ for water or $\mathrm{CuO}+\mathrm{SO}_{3}$ for copper sulphate) into organic chemistry in the 1830s and 40s enabled chemists to "fill gaps" left open by laboratory operations (Klein, 2001: pp. 265-266). First introduced by the Swedish chemist Jacob Berzelius in 1813, chemical formulas proved invaluable in cases where the chemical composition of particular substances could not be definitely identified by methods of experimental analysis, and where it was not possible to measure the masses of reacting substances (Klein, 2001: p. 274). In such cases, the formulas could be "taken as a substitute for the actual measurement of the mass" (p. 275). By the 1840s, this theoretical operation of "substitution”, made possible by the implementation of Berzelian formulas, constituted "an entirely new practice of synthesising organic compounds” (Klein, 2001: p. 290). In what follows, I provide some further examples of how "tool-centred" histories of physics have shed light on the dynamics of scientific change.

\subsection{The Emergence of Microphysics}

In many cases, new tools do not simply appear out of the blue - they are crafted and refashioned from existing ones. Jed Buchwald has suggested that if we are to understand the explosion of interest in the microworld around the turn of $20^{\text {th }}$ century, we need to pay attention not only to the experimental discoveries of cathode rays, $\mathrm{X}$-rays and radioactivity, but also to the development and new tools of theoretical practice. While there had been a long tradition in chemistry and natural philosophy of appealing to hypothetical microphysical structures to explain macroscopic phenomena, it was not until the closing years of the $19^{\text {th }}$ century that physicists began to turn their attention to the investigation of the microworld itself. The new theories of the electron that emerged in the first decade of the $20^{\text {th }}$ century were made possible, not only by the invention of the cathode-ray tube, but by refashioning of the mathematical tools that had been employed in the $19^{\text {th }}$ century tradition of wave optics. As Buchwald explains:

By the end of the 1890s ... the beginnings of a highly heterogeneous, microphysics were forged, a microphysics that provided conceptual, mathematical, and instrumental tools for further investigations. In that sense - in the sense of practice - the microworld first became strikingly real among physicists in the 1890 s... I argue that the modern era of practical microphysics ... was built out of ... the tools and concepts provided by ether dynamics (Buchwald, 2000: p. 214).

Buchwald argues that the tradition of ether wave optics, originating with Fresnel in the 1820s, and developed further by Cauchy, Green, McCullagh, Hemholtz and Drude through the course of the $19^{\text {th }}$ century, was crucial in providing the Dutch physicist Hendrik Lorentz with a set of mathematical tools, which he was able to inventively refashion, that opened up new horizons to the microworld. Here Lorentz was "able to assimilate elements from several different physics cultures” such as Drude's optics and Helmholtz's electrodynamics. Whereas before the end of the 1890s, physicists had physicists had engaged in microphysical reasoning "to elucidate or create the behaviour of macroscopic objects", by the turn of the century, the forging of new theoretical tools, in conjunction with the invention of laboratory instruments such as Thomson's cathode-ray tube, provided physicists with the means to "turn to the microobejcts themselves" (Buchwald, 2000: p. 225).

Galison provides a different perspective of the history of microphysics, in tracing the history of particle detectors from their origins in the Wilson cloud chamber of late Victorian Scotland to the large-scale particle accelerators of the post-war era. Wilson's invention of cloud chamber in 1911, which made possible the discovery of the positron and the muon in the 1930s, dramatically expanded the horizons of knowable in the first few decades of the century. By the 1950s, a host of new instruments had begun to emerge, such as bubble chambers, scintillation counters and particle accelerators, opening up new horizons for the investigation into the sub-atomic world.

In attempting to construct ever more sophisticated particle detectors, the laboratory, as both a physical and cultural space for the production of knowledge of sub-atomic particles, was dramatically reconfigured during the course of the $20^{\text {th }}$ century. It was a place increasingly inhabited by teams of physicists and engineers, belonging to a range of different sub-disciplines. Experimentalists were increasingly confronted with obstacles not only arising from the technical and theoretical constraints of the new instruments, but also epistemological questions about what counted as the detection of a new particle, as well as escalating construction costs, the need for increased manpower and computational power, and the complex social problems arising from the need to coordinate the activities of physicists and engineers with different specializations and technical skills (Galison, 1997). 
The particle physicists of the 1960s found themselves in the midst of a sociological, technological and epistemological revolution.

\subsection{The Rise of Statistical Physics}

A somewhat different picture can be seen in the emergence of statistical and probabilistic tools in physics in the latter part of the nineteenth century. Theodore Porter and Ian Hacking have argued that statistical methods, which first began to emerge in the demographic and biometric studies of human populations in first half of the $19^{\text {th }}$ century, found application in many new areas, crossing disciplinary boundaries into the physical, life and even the cognitive sciences (Porter, 1986, 2008; Hacking, 1990, 2006; Gigerenzer et al., 1990). As Porter explains, physicists in the 1860s "drew selectively from, a statistical tradition that arose within social science, social reform and social administration”, adapting the tools as necessary, to new objects of inquiry (Porter, 2008: p. 492). James-Clerk Maxwell's use of statistical methods to connect thermodynamic behavior of macroscopic systems to microscopic behaviour of molecules, in particular his derivation of the probability distribution law for the speed of molecules in a gas, owed much to this tradition, in particular to Herschel's 1850 essay on Quetelet's Letters on the Theory of Probabilities.

By the beginning of the twentieth century, statistical laws and probabilistic theory had fundamentally transformed the theoretical practice of modern physics. A raft of new mathematical techniques, many of which were developed by Ludwig Boltzmann in the 1870s and 80s building on Maxwell's earlier work, provided a new generation of physicists with a set of tools that could be applied and extended to range of complex problems, which increasingly began to emerge in thermodynamics and the kinetic theory of gases. By the first decade of the $20^{\text {th }}$ century, 'statistical mechanics' had established itself as a new field of physics. More generally, the 'statistical style of reasoning' became widely entrenched. New mathematical techniques, some of which originated in the study of stochastic processes such as stock market fluctuations and in probability theory, gradually found their way into physics. New types of questions, new objects of inquiry, and new kinds of explanations suddenly became possible (Hacking, 1990, 2006). To give but one example, the phenomenon of Brownian motion, which had been first discovered in 1827, became the object of renewed investigation by Einstein, Smoluchowski and Perrin in the first decade of the $20^{\text {th }}$ century, once statistical methods for dealing with large numbers of particles had become available.

\subsection{The Spread of Feynman Diagrams}

We obtain a further insight into the mechanisms by which mathematical tools are transmitted, and in the process refined and extended, in David Kaiser's fascinating study of the spread of Feynman diagrams in $20^{\text {th }}$ century theoretical physics (Kaiser, 2005a). Originally developed by Richard Feynman in the late 1940s as a "bookkeeping device" for simplifying lengthy calculations in quantum electrodynamics, Feynman diagrams had within the space of a decade transformed the landscape of theoretical physics, enabling physicists to "calculate things that many had barely dreamed possible before World War II” (Kaiser, 2005c: p. 42).

While renormalization techniques developed in the 1940s constituted a major advance in quantum electrodynamics, simple problems such as calculating the probability that two electrons will scatter often turned out to be remarkably difficult, due to the problem of infinite virtual self-energy terms. Physicists had to make use of perturbative approximations to solve these kinds of problems, but performing such calculations was often "an algebraic nightmare" and in many cases, they were simply "calculationally intractable”. Feynman diagrams provided a new means of doing what had up until that point had seemed impossible. By the 1960s Feynman diagrams had "revolutionized nearly every aspect of theoretical physics", spreading from quantum electrodynamics to fields such as nuclear and particle physics, solid state physics, and even gravitational physics (Kaiser, 2005c: p. 42).

In understanding how this happened, it is important to note that physicists initially faced serious difficulties in mastering these new techniques. Indeed, many leading theorists were baffled, and Julian Schwinger, Robert Oppenheimer and Niels Bohr remained deeply skeptical about their efficacy. Yet Feynman diagrams triumphed in the 1950s, largely due to the efforts of Freeman Dyson and a new generation of physicists, who acquired the new skills under Dyson's tutelage while undertaking postdoctoral research at the Institute of Advanced Study in Princeton (Kaiser, 2005c: pp. 50-52). After having mastered the new techniques in Princeton, these physicists taught the new skills to their graduate students once they found permanent positions elsewhere. Feynman diagrams came to dominate the practice of post-war theoretical physics by means of a cascading effect of pedagog- 
ical networks, which emanated from Princeton, and spread quickly throughout the United States, to Great Britain and other parts of Europe. As Kaiser explains: "Face-to-face mentoring, rather than the circulation of texts, provided the most robust means of inculcating skill with the new diagrams in expanding groups of users" (Kaiser, 2005c: p. 68). In this way, the spread and advance of the new techniques was inextricably intertwined with "the means by which various scientific practitioners were trained" (Kaiser, 2005c: p. 68).

In acquiring these new skills, physicists began to extend and adapt the use of these diagrammatic techniques into new domains, and in doing so, they departed from the prescribed set of rules for using the diagrams in solving problems of quantum electrodynamics. The emerging field of nuclear particle physics presented altogether new challenges in dealing with the strong force, which could not be handled by means of perturbative calculations. Yet by adding new types of line and pictorial forms, dropping original convention on the use of arrows, and adopting different labeling schemes, physicists began to adapt the diagrams to bring out the relevant features in solving the problems of meson interactions that could not otherwise be solved (Kaiser, 2005c: pp. 60-61). The theoretical practice that emerged in the 1950s was not simply defined by using Feynman diagrams, but also by refashioning and adapting them to a variety of new uses, thereby opening up new possibilities for solving problems in different areas of physics, which up until then had proved to be intractable.

In contrast with the image of scientific change as associated with the emergence of new worldviews or grand new theories, the studies of Klein, Buchwald, Galison, Porter and Kaiser provide a deeper understanding of how scientific traditions of practice are transformed over time, and how new fields of inquiry materialize out of existing ones. Transformations in scientific practice can emerge from attempts to inventively refashion existing tools of inquiry in the pursuit of new goals. It is the capacity of inquirers to see how existing tools and techniques might be put to use, not only in the service of goals they were originally designed for, but in the service of goals they might be redesigned for, that underpins the historicity of scientific practice.

\section{Actor-Centred Histories of Scientific Practice}

\subsection{Bringing the Actors Back on Stage}

In rejecting the "hagiographies of great men", the turn to practice exemplified in sociological and constructivist studies that emerged in the 1980s and 90s systematically removed the individual from centre stage. Yet such approaches were met with resistance from many historians of science, who argued that in forging new alliances with sociology and cultural anthropology, historians had lost sight of the importance of individuality in shaping scientific activity. Judgments about what scientific problems to study, what fields of research are worth pursuing, and how to go about investigating them, are shaped by wider social and cultural contexts, but they also crucially reflect the personal beliefs, temperaments, orientations, motivations, and goals of individual scientists (Kaiser, 1994). The shift from the scientist as "knower" to the scientist as "inquirer" brings into sharp focus the need for actor-centred historiographical approaches as a crucially important resource for the historical understanding of scientific practice.

Historians and sociologists of science have long grappled with the vexing question of how an individual's motivations and actions bear the mark of wider cultural context. Paul Forman's seminal paper, published more than forty years ago, on the emergence of an acausal quantum mechanics in 1926-7 in Weimar Germany has become a locus classicus for these discussions (Forman, 1971). In that paper, Forman argued that a succession of physicists in Weimar Germany had adapted and capitulated to the hostile intellectual environment which found its most powerful expression in Spengler's widely read Decline of the West after the First World War. In adapting to the hostile cultural milieu, physicists took a stance against causality, thus setting in motion a search for a new kind of physics. While Forman's thesis was hugely influential, serving as a major stimulus for the externalist sociology of scientific knowledge, it has become the subject of widespread criticism. Here it is instructive to review how recent critiques of the Forman thesis have provided new historiographical perspectives on the question of 'cultural influences' on the individual.

Much of the initial criticism centred around Forman's almost complete neglect of the particular set of disciplinary problems that had preoccupied quantum physicists in the 1920s. While directing his gaze at the wider cultural context, Forman failed to explore the conceptual, experimental and mathematical tools of the research community. Indeed, quantum mechanics emerged from social networks and research schools that extended beyond Germany into Denmark, Austria and the Netherlands. Moreover, as Michael Stöltzner has argued, many physicists had already taken a stance on causality before the First World War, particularly those who belonged 
to the Viennese tradition of indeterminism inspired by Franz Exner (Stölzner, 2011). Furthermore, whereas Forman had represented Weimar Culture as gripped by a deep and widespread hostility to science, recent scholarship has painted a far more nuanced and heterogeneous picture (Gordon \& McCormick, 2013). Spengler's work undoubtedly captured an important facet of the reaction to modernism, but his work forms only one element in a much more complex array of cultural attitudes, which emerged during the Weimar era.

But there were deeper historiographical issues at stake. Forman's language of "external influence" and "capitulation" conveys the impression of scientists as subject to external forces, which exercise a direct causal influence over their motivations and actions. As Norton Wise, points out, the physicists in Forman's story "are not treated as participants in the culture, or as a subculture nested within it, but stand largely outside it as a separate group” (Wise, 2011: p. 422). Yet, as participants located within a culture, scientists routinely exercise a degree of autonomy in selecting certain available material and cultural resources in pursuing certain goals. While constrained by what is available, scientists may, to a certain extent, "choose their own influences". To quote Wise again:

Thus the primary task for an influence account would be to understand how it is that certain people take on a supposed influence and others do not under very similar circumstances. But that would be a story of individual motivations and choices within a given context, rather than a cultural influence story, and it would place susceptibility and agency in the individual rather than in the culture (Wise, 2011: p. 427).

In Wise's historiographical reconstruction of Forman's model, intellectual biography moves to the centre. What Forman identifies as "sociological influences" here become "resources available to be taken up by particular people for particular purposes, or not, depending on how the individual participated in the culture" (Wise, 2011: p. 427). Considerable progress has made of late in obtaining a deeper understanding the motivations and activities of some of the key physicists that feature prominently in the rise of quantum mechanics on the 1920s. But much still remains to be done in understanding about the way in which this generation of physicists navigated their way through, and shaped, the complex intellectual and cultural terrain of the inter-war period.

\subsection{Scientific Biography as History of Science}

Scientific biography thus constitutes a valuable resource for the historiography of scientific practice. As Stephen Gaukroger writes, intellectual biography must not simply establish a sequence of intellectual pursuits, it must try "to establish a rationale for them both in terms of the subject's motivations and in terms of a specific cultural and intellectual context within which those motivations are shaped and bear fruit" (Gaukroger, 1995: p. 8). It thus becomes the task of the biographer to relate the activities of the individual "to the fields in which the person was active, to the networks that he or she helped to construct, and to the social background conditions that influenced, shaped, or even prompted individual decisions and actions” (Lässig, 2008: pp. 10-11). In this sense, a deeper understanding of an individual's motivations can often be achieved by simultaneously attaining a deeper understanding of the social and cultural context in which the individual worked (Nye, 2006). As John Schuster explains:

Historical actors are best seen as appropriating and interpreting available cultural resources for the attainment of ongoingly renegotiable goals. The array of cultural resources available to an actor is patterned over time by his social location, affiliations and experiences... An actor's trajectory through the domains, fields, and networks which constitute his social environment is open to empirical investigation and theoretical articulation by the historian as to their structures, dynamics and interrelations (Schuster, 2013: p. 15).

Historical actors do not merely appropriate available cultural resources; they continually "reinterpret" them, and "renegotiate goals", thereby "moulding the very environments in which they move” (Schuster, 2013: p. 15). This kind of historiographical approach has informed much recent biographical work in the history of $19^{\text {th }}$ century science. Crosbie Smith and Norton Wise have argued that William Thomson's interest in the industrial problems of practical telegraphy provided conceptual and material resources for his laboratory practice in Glasgow (Smith \& Wise, 1989). Faraday's experimental investigations, as Geoffrey Cantor has argued, were inspired and guided by deep religious and theological convictions, which reflected his affiliation with the Sandemanian community in London (Cantor, 1991). More recently, Giuliano Pancaldi has argued that Volta's scientific endeavours, which resulted in his invention of the voltaic pile in 1800, can be understood by situating him 
within the contexts of the cosmopolitan network of the Republic of Letters and the emerging material culture of technological innovation (Pancaldi, 2003). The figure that emerges from Pancaldi's study of Volta, is one inspired by the values of the Enlightenment, in prefiguring the eclipse of the "natural philosopher" and the rise of the "scientist" in the $19^{\text {th }}$ century.

Recent scholarship on Hans Christian Ørsted has revised earlier views of the motivations that lay behind his program of experimental research, which resulted in his celebrated discovery of electromagnetism in 1820 (Stauffer, 1957; Gower, 1973, 2005). While Ørsted has often been portrayed as the archetypal 'Romantic natural philosopher', recent studies have painted a far more nuanced picture of the way in which he positioned himself in relation to the various strands of German idealism he encountered in the works of Kant, Fichte and Schelling, his relationship to Romanticism and the dynamical philosophy, as well as the significance he attached to the electrochemical discoveries of his day, and his overarching vision of a theology of nature (Brain et al., 2007). Understanding Ørsted's practice as a natural philosopher requires us to understand the way he selectively appropriated these cultural resources, in forging his own unique approach in striving to uncover the unity of forces in nature.

\subsection{Investigative Pathways}

Biographical studies have also revealed aspects of individual research by focusing on what Frederic Holmes has called the "fine structure" of creative scientific activity. These approaches attempt to reconstruct the 'investigative pathway' of a single individual extending over periods of time sometimes lasting several years. As Jan Golinski explains, historians have become increasingly attentive to "openness and uncertainties" of scientific practice, in attempting to reconstruct "the experience of the unfolding of investigative research over the course of time” (Golinski, 2005: p. 195). By drawing on the accounts contained in correspondence, manuscripts, and laboratory notebooks where available, it is possible to follow the biographical trajectory of research pursued by individuals. Studies of investigative pathways of Lavoisier, Ampère and Faraday have revealed the way in which individuals become deeply immersed in their research, which can often lead them in new and unexpected directions (Gooding, 1990; Steinle, 2003; Holmes, 2004, 2009).

The study of investigative pathways provides a quite different perspective into the acquisition of experimental skill. David Gooding has argued, "Faraday was an effective experimentalist because he was able to use information acquired in the course of making an experiment work" (Gooding, 1985: p. 106). Faraday learned his craft as an experimentalist in his formative years under the tutelage of his mentor Humphrey Davy, however his gift of isolating novel phenomena was learned in "nature's school". In many cases, "Faraday had laboured for hours, days and weeks to acquire the skills necessary to produce these effects" (Gooding, 1985: p. 107). The skills necessary for successfully engaging in scientific research can often not be simply learned from others by means of pedagogical networks, but emerge in the course of experimental practice. In this sense, the transformation of the scientific self occurs in and during the very activity of inquiry.

In the course of their investigations, researchers will pursue any one of a number of epistemic goals - the construction of a new instrument; the theoretical explanation of a certain effect; the detection or classification of a new type of entity; the formulation of an empirical regularity or physical law; the experimental investigation of a puzzling new phenomenon; or the measurement of a certain quantity. Yet, researchers may encounter obstacles or unexpected, intriguing or novel phenomena, which divert their attention or reorient their inquiries. ${ }^{1}$ In such circumstances, new goals may emerge, and existing goals may be revised or even abandoned-in a dialectic process that Andrew Pickering has termed "the mangle of practice" (Pickering, 1995). As Hans-Jörg Rheinberger explains, it is often the case that, in the course of research, "findings regarded as prominent at a particular time recede into the background at another", and questions initially "regarded as important remain unsolved and eventually become marginalized, if not forgotten altogether, whereas others move centre stage” (Rheinberger, 2009: p. 76). This is the common experience of the individual researcher.

\footnotetext{
${ }^{1}$ The discovery of the photoelectric effect by Heinrich Hertz in 1887 provides one striking example. In the course of Hertz's experiments to detect the presence, reflection and refraction of electromagnetic radiation emitted from an oscillating electric charge, he noticed certain puzzling effects in the electric sparks in the receiver. Intrigued by the phenomenon, Hertz embarked upon a more thorough investigation, which revealed that ultraviolet light made the spark more visible, though Hertz offered no theoretical explanation of why. What initially appeared as a 'technical accident' now became the primary object of investigation. This discovery led immediately to a series of further experimental investigations by Hallwachs, Hoor, Righi, Stoletow and Leonard on the effect of light on charged bodies. There is a certain irony here. Hertz's experimental work, which provided conclusive evidence for the existence of electromagnetic waves, set in train a series of investigations that ultimately led to Einstein's postulation of light quanta.
} 
However, amidst the flux of shifting immediate, partial and short-term goals, it may be possible to discern a deeper aim or purpose in the work of an individual, which endures over a significantly longer period of time. Such aims may be said to constitute 'the motivating force of inquiry' that guide the direction of overarching programs of experimental or theoretical research. These aims originate, in part, in certain cultural traditions, discursive and material practices, and in the constellation of values that form the wider context in which scientists live and work. But, importantly, they also emerge from an individual's personality and temperament. Frederic Holmes has suggested that the "coherence and persistence of the individual investigative pathway" may reveal "deeper psychological foundations". "Whenever we identify ourselves with certain goals and pursue them for a time, they tend to become part of our own identities, and we tend to continue along the pathways begun in order to remain ourselves” (Holmes, 2009: p. 72).

\section{The Virtues of Historiographical Pluralism}

What lessons, if any, can we draw about the preceding selective survey of different approaches to the dynamics of scientific practice? The last thirty years has witnessed a proliferation of different historical studies of various aspects of scientific practice, which have made in difficult to draw any clear lessons or conclusions. The three historiographical approaches I have presented here address different aspects of the nature of scientific practice, its patterns and processes of change, and its dynamics and structures, which correlate with different modes of historical explanation. "Tradition-centred” historical approaches have proved invaluable in bringing to light the ways in which scientific inquiry is structured and patterned, the ways in which traditions are sustained through systems of training and pedagogy, and how the wider social and political context may shape the formation of different epistemic styles. A deeper understanding of how such traditions change over time may be gained by shifting one's historical focus to a "tool-centred" historical approach. Here the historian can trace in detail the ways in which new tools and techniques are forged out of exiting ones, in some cases making entirely new fields of inquiry possible. Such an approach is better suited to understanding the long-term dynamics of scientific change. Yet such accounts leave the particular motivations, judgments, and choices of the individuals unexplained, and it is here that "actor-centred” approaches prove their worth in historical analysis.

The examples presented here raise important historiographical questions about how, and in what sense, context "shapes" scientific practice. Discussions of the contextual explanations have often found themselves trapped in the outmoded vocabulary of the internalist/externalist dichotomy, which have tended to see "internalism" and "externalism" as different causal theories of scientific change. The former portrays the progress of science as determined by its own internal logic, while the later, with its historical roots in Marxist history, identifies the cause of scientific change with external social and economic forces. While much contemporary historical scholarship no longer explicitly invokes these categories of historical analysis, a number of historians have questioned whether present-day contextualist approaches "really constitute a definite advance" in transcending the internalist/externalist debate (Schuster, 2000: p. 336). One reason for this, as Steven Shapin pointed out more than twenty years ago, is that historians of science "never systematically interrogated, defined and defended modes of causative action presupposed by each theory of scientific change” (Shapin, 1992: p. 349).

The focus on scientific practice, however, provides us with an opportunity to reflect more carefully on how, and in what sense, we may appeal to 'historical context' in explaining the emergence of activities of individuals and the formation of scientific cultures or traditions (Galison, 2008). Whereas internalism and externalism have often been presented as causal theories of scientific change, the invocation of "context" as an explanatory historical category is best understood in a range of different senses. Here I identify three different ways in which the recent historical scholarship I have focused on has made use of contextual explanations.

First, the appeal to "cultural context" may refer to certain traditions of practice in which someone is trained or enculturated. Certain "styles of inquiry”, or "ways of working” may be transmitted to the individual by means of formal or informal pedagogical networks or wider social structures, which tend to inculcate certain abilities or patterns of behaviour. Such contexts shape the individual from within. While training "does not completely determine" how scientists will tackle a new problem, "it conditions how they will approach the problem" (Warwick \& Kaiser, 2005: p. 401). Secondly, we may speak of the wider social, political or economic context, in which traditions of practice take shape. These typically refer to the conditions under which certain forms of inquiry arise. Contextual explanations of this kind, as Elwick notes, should not be construed as causal explanations. Rather, they refer to historically contingent conditions, under which certain forms of scientific practice 
become possible (Elwick, 2012). Thirdly, we may speak of a context as referring to the existence of certain cultural resources, which may be available to an individual by virtue of his or her social location, experiences, or affiliations. Here again, contexts are not causes. The susceptibility of certain individuals to the influence of certain elements in their social environments is partly a reflection of their temperament, life experience and predispositions.

A deeper understanding of scientific practice, its structure, dynamics, conditions of possibility, thus requires the full array of tools and methods available to the historian. Here I write in sympathy with Brian Baigire, who has pointed out that the temptation to seek out overarching "general philosophical frameworks for coming to grips with the activities of scientists inadvertently reinforces the very unitary conception of scientific practice that many scholars are trying to dismantle” (Baigrie, 1995: p. 121). Like scientists, historians too are actors, who must utilise the historiographical resources we have at our disposal. I am not advocating here that the historian must become a "jack of all trades". Nor do I deny that different historiographical approaches may sometimes lead to different, or even conflicting, accounts. The point is simply that the choice of historiographical approach will invariably depend on what aspect of scientific practice we are most interested in, and what we take to be the “object of inquiry”. Much of the confusion results from a failure to clearly define what we are treating as the $e x$ planans and the explanandum of a historical explanation, and the ways this may shift in the unfolding of a historical narrative.

\section{Conclusion}

In concluding, I would like to suggest that in defending a form of historiographical pluralism, I take my inspiration from what we have been able to learn about the scientific enterprise itself. One of the illusions that has come unraveled in recent decades, at least in the Anglophone world, has been the myth of a universal scientific method, or what has become known as the "single science model". Of course this insight has long been part of the French tradition, finding its clearest expression in the work of Comte and Bachelard. One happily speaks nowadays of different "ways of knowing”, "styles of reasoning”, “quasi-autonomous sub-cultures”, or "research schools" and "research traditions" within the sciences. This is not to suggest there is no unity in the sciences, merely that we can no longer expect to find it in the naïve idea of some kind of universal rationality. As Galison points out, "it is precisely the disunification of science that underpins its strength and stability” (Galison, 1999: p. 137). Here I would argue the same is true of the historical enterprise. Its strength, to some extent, lies in its disunity.

We may take this analogy a step further. In Galison's view, physics comprises of quasi-independent subcultures, each of which engage in "different patterns of argument", but which trade with one another. Over the course of the $20^{\text {th }}$ century, experimental and theoretical physics increasingly came to constitute distinctive fields of specialization, but they remained interlocked in continuous exchange. Historical work, in this sense, is no different. Cultural history, intellectual biography, fine-grained technical studies, and historical methods drawing on the resources of cultural anthropology and historical sociology, can and should mutually benefit one another. To change the analogy somewhat, the "image of scientific practice" that has slowly begun to emerge from historical studies might be likened to what Darden and Maul have called "interfield theories” in biology (Darden \& Maull, 1977). Only by combining different of fields and methods of research does it become possible to bring to light the many different aspects of the same phenomenon.

\section{Acknowledgements}

I would like to thank John Schuster for his clarifying remarks on the special issue and his words of encouragement in preparing this paper.

\section{References}

Baigrie, B. (1995). Scientific Practice: The View from the Tabletop. In J. Buchwald (Ed.), Scientific Practice: Theories and Stories of Doing Physics (pp. 87-122). Chicago, IL: Chicago University Press.

Brain, R., Cohen, R. S., \& Knudsen, O. (Eds.) (2007). Hans Christian Ørsted and the Romantic Legacy in Science. Dordrecht: Springer. http://dx.doi.org/10.1007/978-1-4020-2987-5

Buchwald, J. (2000). How the Ether Spawned the Microworld. In L. Daston (Ed.), Biographies of Scientific Objects (pp. 203-225). Chicago, IL: Chicago University Press. 
Buchwald, J. (Ed.) (1995). Scientific Practice: Theories and Stories of Doing Physics. Chicago, IL: Chicago University Press.

Buchwald, J., \& Hong, S. (2003). Physics. In D. Cahan (Ed.), From Natural Philosophy to the Sciences: Writing the History of Nineteenth Century Science (pp. 163-195). Chicago, IL and London: University of Chicago Press.

Caneva, K. L. (1978). From Galvinism to Electrodynamics: the Transformation of German Physics and its Social Context. Historical Studies in the Physical Sciences, 9, 63-159. http://dx.doi.org/10.2307/27757377

Cantor, G. (1991). Michael Faraday: Sandemanian and Scientist: A Study of Science and Religion in the Nineteenth Century. Basingstoke, Hampshire: Macmillan.

Chang, H. (2011). Compositionalism as a Dominant Way of Doing Chemistry. History of Science, 49, 247-268.

Darden, L., \& Maull, N. (1977). Interfield Theories. Philosophy of Science, 44, 43-64. http://dx.doi.org/10.1086/288723

Daston, L., \& Galison, P. (2007). Objectivity. New York: Zone Books.

Dewey, J. (1986). Logic: The Theory of Inquiry. In J. A. Boydston (Ed.), John Dewey: The Later Works: 1925-1953 (Vol. 12). Carbondale, IL: SIU Press.

Elwick, J. (2012). Layered History: Styles of Reasoning as Stratified Conditions of Possibility. Studies in History and Philosophy of Science, 43, 619-627. http://dx.doi.org/10.1016/j.shpsa.2012.07.004

Feest, U., \& Sturm, T. (2011). What (Good) Is Historical Epistemology? Erkenntnis, 75, 285-302. http://dx.doi.org/10.1007/s10670-011-9345-4

Forman, P. (1971). Weimar Culture, Causality and Quantum Theory, 1918-1927: Adaption by German Physicists and Mathematicians to a Hostile Intellectual Environment. Historical Studies in the Physical Sciences, 3, 1-115.

http://dx.doi.org/10.2307/27757315

Foucault, M. (1977). Discipline and Punish. New York: Pantheon Books.

Fox, R. (1974). The Rise and Fall of Laplacian Physics. Historical Studies in the Physical Sciences, 4, 89-136. http://dx.doi.org/10.2307/27757328

Frankel, E. (1977). J. B. Biot and the Mathematization of Experimental Physics in Napoleonic France. Historical Studies in the Physical Sciences, 8, 33-72. http://dx.doi.org/10.2307/27757367

Galison, P. (1997). Image and Logic: A Material Culture of Microphysics. Chicago, IL: University of Chicago Press.

Galison, P. (1999). Trading Zone: Coordinating Action and Belief. In M. Biagioli (Eds.), Science Studies Reader (pp. 137160). New York: Routledge.

Galison, P. (2008). Ten Problems of History and Philosophy of Science. Isis, 99, 111-124. http://dx.doi.org/10.1086/587536

Galison, P., \& Warwick, A., (1998). Introduction: Cultures of Theory. Studies in History and Philosophy of Modern Physics, 29, 287-294.

Gaukroger, S. (1995). Descartes: An Intellectual Biography. Oxford: Clarendon Press.

Gigerenzer, G., Swijtink, Z., Porter, T., Daston, L., Beatty, J., \& Kruger, L. (1990). The Empire of Chance: How Probability Changed Science and Everyday Life. New York: Cambridge University Press.

Golinski, J. (1990). Theories of Practice and the Practice of Theory: Sociological Approaches in the History of Science. Isis, 81, 492-505. http://dx.doi.org/10.1086/355457

Golinski, J. (2005). Making Natural Knowledge: Constructivism and the History of Science. Chicago, IL:: University of Chicago Press. http://dx.doi.org/10.7208/chicago/9780226302324.001.0001

Gooding, D. (1985). “In Nature’s School”: Faraday as an Experimentalist. In D. Gooding, \& F. A. James (Eds.), Faraday Rediscovered: Essays on the Life and Work of Michael Faraday 1791-1867 (pp. 105-135). London: Macmillan.

Gooding, D. (1990). Experiment and the Making of Meaning: Human Agency in Scientific Observation and Experiment. Dordrecht, Boston: Kluwer. http://dx.doi.org/10.1007/978-94-009-0707-2

Gordon, P., \& McCormick, J. (2013). Weimar Thought: A Contested Legacy. Princeton, NJ: Princeton University Press.

Gower, B. (1973). Speculation in Physics: The History and Practice in Naturphilosophie. Studies in History and Philosophy of Science Part A, 3, 301-356. http://dx.doi.org/10.1016/0039-3681(73)90015-0

Gower, B. (2005). The Metaphysics of Science in the Romantic Era. In D. Knight, \& M. Eddy (Eds.), Science and Beliefs: From Natural Philosophy to Natural Science, 1700-1900 (pp. 17-29). Bulington, VT: Ashgate.

Hacking I. (2006). The Emergence of Probability: A Philosophical Study about Early Ideas about Probability, Induction and Statistical Inference. Cambridge, New York: Cambridge University Press. http://dx.doi.org/10.1017/CBO9780511817557

Hacking, I. (1990). The Taming of Chance. New York: Cambridge University Press. http://dx.doi.org/10.1017/CBO9780511819766 
Heilbron, J. (1990). Introductory Essay. In T. Frängsmyr, J. Heilbron, \& R. Rider (Eds.), The Quantifying Spirit in the 18th Century (pp. 1-23). Berkeley, Los Angeles, Oxford: University of California Press.

Holmes, F. (2004). Investigative Pathways: Patterns and Stages in the Careers of Experimental Scientists. New Haven, CT: Yale University Press.

Holmes, F. (2009). Experimental Systems, Investigative Pathways and the Nature of Discovery. In J. Mehus, \& T. Nickles (Eds.), Models of Discovery and Creativity (pp. 65-79). Dordrecht: Springer.

http://dx.doi.org/10.1007/978-90-481-3421-2 5

Kaiser, D. (1994). Bringing the Actors Back on Stage: The Personal Context of the Einstein-Bohr Debate. British Journal for the History of Science, 27, 129-152. http://dx.doi.org/10.1017/S0007087400031861

Kaiser, D. (2005a). Drawing Theories Apart: The Dispersion of Feynman Diagrams in Postwar Physics. Chicago, IL: The University of Chicago Press. http://dx.doi.org/10.7208/chicago/9780226422657.001.0001

Kaiser, D. (2005c). Making Tools Travel: Pedagogy and the Transfer of Skill in Postwar Theoretical Physics. In D. Kaiser (Ed.), Pedagogy and the Practice of Science: Historical and Contemporary Perspectives (pp. 41-74). Cambridge, MA: The MIT Press.

Kaiser, D. (2005b). Introduction: Moving Pedagogy from the Periphery to the Center. In D. Kaiser (Ed.), Pedagogy and the Practice of Science: Historical and Contemporary Perspectives (pp. 1-8). Cambridge, MA: The MIT Press.

Klein, U. (2001). Paper Tools in Experimental Cultures. Studies in History and Philosophy of Science, 32, 365-302. http://dx.doi.org/10.1016/S0039-3681(01)00010-3

Lässig, S. (2008). Introduction: Biography in Modern History-Modern Historiography in Biography. In V. Bergham, \& S. Lässig (Eds.), Biography between Structure and Agency: Central European Lives in International Historiography (pp. 1-26). New York, Oxford: Bergham Books.

Maienschein, J. (1991). Epistemic Styles in German and American Embryology. Science in Context, 4, 407-477. http://dx.doi.org/10.1017/S0269889700001034

Nye, M. J. (1993). National Styles? French and English Chemistry in the Nineteenth and Twentieth Centuries. Osiris, 8, 3049. http://dx.doi.org/10.1086/368717

Nye, M. J. (2006). Scientific Biography: History of Science by Another Means? Isis, 97, 322-329. http://dx.doi.org/10.1086/504738

Olesko, K. (1991). Physics as a Calling: Discipline and Practice in the Königsberg Seminar for Physics. Ithaca, NY: Cornell University Press.

Olesko, K. (2006). Science Pedagogy as a Category of Historical Analysis: Past, Present, and Future. Science and Education, 15, 863-880. http://dx.doi.org/10.1007/s11191-005-2014-8

Oreskes, N., \& Doel, R. E. (2008). The Physics and Chemistry of the Earth. In M. Nye (Ed.), The Cambridge History of Science, Vol. 5, The Modern Physical and Mathematical Sciences (pp. 538-557). Cambridge: Cambridge University Press.

Pancaldi, G. (2003). Volta: Science and Culture in the Age of Enlightenment. Oxford: Oxford University Press.

Pickering, A. (1995). The Mangle of Practice: Time, Agency, and Science. Chicago, IL: University of Chicago Press. http://dx.doi.org/10.7208/chicago/9780226668253.001.0001

Pickering. A. (Ed.) (1992). Science as Practice and Culture. Chicago, IL: University of Chicago Press.

Porter, T. (1986). The Rise of Statistical Thinking: 1820-1900. Princeton, NJ: Princeton University Press.

Porter, T. (2008). Statistics and Physical Theories. In M. Nye (Ed.), The Cambridge History of Science: Vol. 5, The Modern Physical and Mathematical Sciences (pp. 488-504). Cambridge: Cambridge University Press.

Rheinberger, H.-J. (2009). Experimental Reorientations. In G. Hon, J. Schickore, \& F. Steinle (Eds.), Going Amiss in Experimental Research (pp. 75-90). New York: Springer. http://dx.doi.org/10.1007/978-1-4020-8893-3_6

Rouse, J. (2003). Thomas Kuhn’s Philosophy of Scientific Practice. In T. Nickles (Ed.), Thomas Kuhn (pp. 101-121). Cambridge: Cambridge University Press.

Schuster, J. (2000). Internalist and Externalist Historiographies of the Scientific Revolution. In W. Applebaum (Eds.), The Encyclopedia of the Scientific Revolution: From Copernicus to Newton (pp. 334-6). UK: Taylor \& Francis.

Schuster, J. (2013). Descartes-Agonistes: Physico-Mathematics, Method \& Corpuscular Mechanism 1618-1633. Dordrecht: Springer. http://dx.doi.org/10.1007/978-94-007-4746-3

Seth, S. (2010). Crafting the Quantum: Arnold Sommerfeld and the Practice of theory, 1896-1926. Cambridge, MA: MIT Press.

Shapin, S. (1992). Discipline and Bounding: The History and Sociology of Science as seen through the Externalism-Internalism Debate. History of Science, 30, 333-369. 
Sibum, O. (1995). Reworking the Mechanical Value of Heat: Instruments of Precision and Gestures of Accuracy in Early Victorian England. Studies in History and Philosophy of Science, 26, 73-106. http://dx.doi.org/10.1016/0039-3681(94)00036-9

Smith, C., \& Wise, M. N. (1989). Energy and Empire: A Biographical Study of Lord Kelvin. Cambridge, New York: Cambridge University Press.

Stauffer, R. C. (1957). Speculation and Experiment in the Background of Oersted's Discovery of Electromagnetism. Isis, 48, 33-50. http://dx.doi.org/10.1086/348537

Steinle, F. (2002). Experiments in History and Philosophy of Science. Perspectives on Science, 10, 408-432. http://dx.doi.org/10.1162/106361402322288048

Steinle, F. (2003). The Practice of Studying Practice: Analyzing Research Records of Ampère and Faraday. In F. Holmes, J. Renn, \& H.-J. Rheinberger (Eds.), Reworking the Bench: Research Notebooks in the History of Science (pp. 93-117). Dordrecht: Kluwer.

Stölzner, M. (2011). The Causality Debates of the Interwar Years and Their Preconditions: Revisiting the Forman Thesis from a Broader Perspective. In C. Carson, A. Kojevnikov, \& H. Trischler (Eds.), Weimar Culture and Quantum Mechanics. Selected Papers by Paul Forman and Contemporary Perspectives on the Forman Thesis (pp. 502-22). London: Imperial College Press.

Vicedo, M. (1995). Scientific Styles: Toward Some Common Ground in the History, Philosophy, and Sociology of Science. Perspectives on Science, 3, 231-254.

Warwick, A. (2003). Masters of Theory: Cambridge and the Rise of Mathematical Physics. Chicago, IL: The University of Chicago Press. http://dx.doi.org/10.7208/chicago/9780226873763.001.0001

Warwick, A., \& Kaiser, D. (2005). Kuhn, Foucault, and the Power of Pedagogy. In D. Kaiser (Ed.), Pedagogy and the Practice of Science: Historical and Contemporary Perspectives (pp. 393-409). Cambridge, MA: The MIT Press.

Wise, M. N. (2011). Forman Reformed Again. In C. Carson, A. Kojevnikov, \& H. Trischler (Eds.), Weimar Culture and Quantum Mechanics. Selected Papers by Paul Forman and Contemporary Perspectives on the Forman Thesis (pp. 415-432). London: Imperial College Press.

Wise, M. N. (Ed.) (1997). The Values of Precision. Princeton, NJ: Princeton University Press.

Zittel, C. (2012). Ludwik Fleck and the Concept of Style in the Natural Sciences. Studies of Eastern European Thought, 64, 53-79. http://dx.doi.org/10.1007/s11212-012-9160-8 